\title{
Questão urbana na "Era Lula": roteiros do impasse político
}

(MARICATO, E. O impasse da política urbana no Brasil. Petrópolis: Vozes, 2011)

1. Professor na Faculdade de Ciências Sociais, UFG
Pedro Célio Alves Borges ${ }^{1}$

$\mathrm{N}$ o seu conhecido estudo sobre o engajamento político-social dos intelectuais brasileiros, nos anos 1950 e 1960, Daniel Pécaut identificou a vertente daqueles que se entregam à ação política sem hesitação, sabedores de possuírem qualificação especial para fazê-lo. Segundo o autor, nas experiências da época, os intelectuais viveram percalços, interditos e confrontos - nem sempre de racionalidade similar à de seu ofício - que acabavam desviando-os do impulso original. Em muitos casos, eles se afastavam da articulação orgânica em partidos e movimentos e conduziam sua verve militante a outros caminhos, inclusive àqueles em que retóricas jacobinas, de denuncismo e niilismo, tomavam o lugar das proposições estratégicas para o país.

No livro O impasse da política urbana no Brasil (Petrópolis: Vozes, 2011 - 219 p.), Ermínia Maricato reafirma sua trajetória fortemente impregnada aos embates político-intelectuais que estruturaram o campo dos estudos urbanos no Brasil contemporâneo. Há, nele, artigos com reflexões de fôlego e bem documentadas, entrecortadas por tons de depoimento e balanço, que ilustram o primeiro tipo mencionado acima e distanciam-na do segundo - não obstante a autora delimitar seus objetos nas rupturas, ela declara com as razões hegemônicas adotadas para a institucionalização da democracia no país. A contundência de suas críticas e temores não se rende, entretanto, à tentação de recusa radical do político, como adiante veremos.

Mais especificamente, localiza-se no vínculo com as lutas pela reforma urbana, travadas desde meados dos anos 1970, o fator de proeminência da contribuição teórica e política de Maricato. A combinação do rigor de pesquisadora da FAUUSP, há 36 anos, com o compromisso da ativista dos movimentos sociais para alterar os padrões de gestão das cidades brasileiras fornece o pano de fundo para a leitura dos capítulos. E aqui poderíamos, mesmo, dispensar a explicitação de credenciais, dado o reconhecimento com que se costuma contextualizar as intervenções da autora. Aos menos informados na área basta mencionar, por exemplo, que boa proporção das elaborações e iniciativas conducentes à criação no Brasil, do Estatuto da Cidade, em 2001, e daí a dois anos, do Ministério das Cidades tiveram sua coordenação criativa e intensa. 
Por isso, as imbricações entre teoria e intencionalidades que, em diferentes momentos, moveram a produção dos textos, configurando a unidade narrativa do volume, estabelecem um ângulo privilegiado para se lidar com os entrelaçamentos entre questão urbana e política no Brasil, transcorridos na efervescência do período aberto pela democratização do final dos anos 1970 e se estende até o segundo Governo Lula. Trata-se, em outras palavras, de uma retrospectiva bem informada e analítica de momentos fortes em que a esquerda se prepara para protagonizar, ainda que não exclusivamente, as tarefas estratégicas de Estado.

Cinco capítulos abordam diferentes facetas no debate da política urbana. O primeiro traduz, em letras explícitas, a proposta do livro, inclusive empresta título ao conjunto. Suas teses e categorias sustentam argumentos formados, ainda, no calor de controvérsias acerca dos dramas que assolam nossas cidades, ademais, de guiarem a compreensão dos outros capítulos, dedicados a recortes específicos do urbano. Na verdade, eles constituem fragmentos datados das já conhecidas contribuições de Maricato nos campos dos movimentos sociais ("Nunca fomos tão participativos") e da estrita reflexão acadêmica ("Formação e impasse do pensamento crítico sobre a cidade periférica"), sendo os dois últimos, dirigidos a públicos mais amplos ("O automóvel e a cidade" e "A terra é o nó"). Sem prejuízo da compreensão, cada capítulo pode ser lido fora da sequência exposta no sumário. Justifica-se, por conseguinte, a fixação da resenha nos conteúdos do texto inicial.

Nele, percebe-se um tom de crítica severa aos processos e escolhas que subordinaram a política urbana do período ao jogo político geral. Em particular, os alvos são "os desvios de percurso", contrários à reforma urbana, acontecidos no contexto do Governo Lula. A sensação é de que o balanço feito presta-se a um ajuste de contas, como se atendesse a uma autocrítica da própria atuação - e da impotência - de Maricato como agente de governo. Não obstante, o terreno é mais fértil e estimula outros sentidos, notadamente mais marcantes que este. Através do encadeamento factual, estrutura-se uma bem conduzida interpretação de conjuntura, em que prevalece a sobriedade dos que conseguem compreender que, no fechamento de um ciclo negativo, podem emergir alternativas para reinserção na arena política. A perspectiva de quem viveu os acontecimentos "de dentro" dirige a narrativa, com evidentes ganhos para a leitura.

Uma síntese dos argumentos, remissões e tratamento empírico caracterizadores do impasse da política urbana percebe-se neste trecho:

Acabou-se um ciclo que prenunciava reformas urbanas, em especial a reforma fundiária e imobiliária. A experiência das "prefeituras democráticas e populares" parece ter chegado ao limite. A produção acadêmica crítica está num 
impasse. Grande parte dos movimentos sociais e sindicais está contida entre o pragmatismo e o corporativismo. Os mais combativos estão sob pressão da mídia, do agronegócio e dos numerosos processos jurídicos de criminalização. (p. 9)

Trata-se, em suma, de um impasse político, que agrega notórias conotações institucionais, técnicas, teóricas e ideológicas, se assim for possível, decompor analiticamente a política, uma instância formada por lastros internos indissolúveis uns dos outros.

O componente institucional traduz-se claramente nas referências aos oito primeiros anos do Ministério das Cidades, onde a autora foi ministra-adjunta entre 2003 e 2005. Mais do que o cargo, ou também por intermédio dele, Maricato foi efetiva porta-voz da aposta de ampla gama de movimentos sociais e de técnicos do serviço público comprometidos com a reforma urbana. Sua retirada do proscênio ocorre em resposta à solução tomada no Governo Lula, de converter o ministério (e a questão habitacional) em moeda de troca nas negociações políticas no interior do Congresso Nacional. Os acúmulos institucionais consumados, até então, na guerra de posição da política urbana caem na órbita do conservadorismo do Partido Popular e, para a autora, conhecem entraves de difícil reversão. A respeito desse novo momento da hegemonia lulista emerge a amarga conclusão, de que "o destino das cidades brasileiras [de segregação social, degradação ambiental, trânsito caótico, especulação financeira sobre a terra, negação da cidadania às amplas maiorias, etc.] está longe de mudar de rumo". Confirma-se, através dessa sentença, que a questão urbana ou metropolitana não constou nas prioridades do Governo Lula. Mais ainda, que, muitas vezes, o seu ministério resulta submetido a ditames do Ministério da Fazenda e/ ou da Casa Civil.

As implicações técnicas do impasse evidenciam-se, principalmente, pelo roteiro dado à ação de maior ressonância social da chamada era Lula, o Programa Minha Casa Minha Vida (PMCMV). Lançado em 2009, esse programa retroage face aos conceitos norteadores do PAC de 2007, que, nas maiores cidades, buscavam um sentido holístico para inscrever a urbanização de favelas e a moradia social, em geral, ao desenvolvimento urbano envolvente. Na contramão desse vínculo, favorável à integração e acesso das maiorias pobres aos benefícios de viver na cidade, o PMCMV começa por incluir, na autoria da proposta, as 11 maiores empresas de promoção de moradia no país. Culmina com a formulação dos critérios para localização dos novos conjuntos habitacionais populares. Nas cidades e municípios, esses locais serão definidos por agentes de mercado, seguindo lógicas do mercado. Os resultados são de conhecimento antigo e, portanto, previsíveis: aglomerados isolados erigidos "no meio do nada, tendo uma rodovia estadual como único contato com a cidade consolidada e os polos de 
emprego, educação e serviços" (p. 68). Além disso, o PMCMV adere a outra demanda dos empresários do setor, ao estender a sua faixa de atendimento, originalmente projetada para famílias na faixa de renda de 0 a 3 salários mínimos (proporção de $90 \%$ no déficit de moradias), para faixas entre 7 a 10 salários mínimos. Em outras palavras, torna evidentes os riscos de repetir o que muito se criticava no antigo $\mathrm{BNH}$, de atender classes médias em detrimento das classes baixas.

O plano teórico de Maricato aproveita o cruzamento de distintas angulações, que remetem a reflexão aos eixos da tradição patrimonialista da sociedade brasileira e da renda fundiária urbana. Nesse enquadramento, Maricato demonstra os processos que levam as políticas urbanas a reafirmarem mecanismos do Estado brasileiro, useiros e vezeiros na função de concentrar renda, de capturar recursos públicos para alimentar o mercado e servir ao conforto e investimentos das camadas médias e de mais alta renda. Mesmo considerando na balança os significativos avanços a ela contrários, registrados no Governo Lula, essa irresistível tendência histórica não é superada. Ao contrário, nele sobressai a marca da ambiguidade, na medida em que suas orientações atendem, ao mesmo tempo, aos movimentos sociais, com a criação do Fundo Nacional de habitação de Interesse Social (FNHIS), e aos empresários, com o PMCMV, nos moldes acima tratados.

Tal ambiguidade conforma meios para deslindar, ainda, um singular viés ideológico do impasse político. Se, em alguns aspectos relevantes, a orientação neoliberal vigente no período anterior é modificada, em particular com a retomada do Estado forte ao modo varguista, na política urbana de Lula os rumos essenciais são mantidos. Especialmente no segundo mandato, a orientação desenvolvimentista assumida com Dilma à frente da Casa Civil e Mantega na Fazenda, que faz elevar a taxa de juros a 26,5\%, fornece base, segundo Maricato, para a transferência de ativos do Estado ao mercado e, para completar, a financeirização dos programas habitacionais, com impactos na valorização fundiária urbana.

Fecha-se, assim, a contextualização da política urbana e de seu impasse, traduzido na hipótese de que as bandeiras da reforma urbana "bateram no teto", neutralizadas ou subsumidas no momento histórico que a elas mais se apresentava promissor, do ponto de vista político. Em particular no segundo mandato, a estagnação no tratamento de conteúdos essenciais para a vida das cidades descambou para o retrocesso.

Como observação final, ressalte-se a dificuldade de, ao cabo da leitura do capítulo-mestre do livro, escapar do pessimismo que o transpassa e transborda para os demais textos. Maricato mostra-se ciente da encruzilhada. 
E é como intelectual e militante que teima em reiterar as tarefas que o Governo "deixou de realizar", na forma de utopias, para superar o que ela, numa infeliz figuração terminológica, denomina de "analfabetismo urbano" (p. 45).

Independente de ser lido como avaliação objetiva de uma conjuntura (repetindo, avaliação consistente pautada em rigor analítico e robustez empírica) ou como manifesto de quem professa um projeto, impõe-se registrar que o "impasse da política urbana no Brasil" surge abalizado por uma autoria que só é possível alcançar através da vivência comprometida. Retomando Pécaut, sua elaboração reflete, como hipótese, a condição do trabalho intelectual que "ou se identificando com o Estado ou se apresentando como anti-Estado", não hesita em correr os riscos de se envolver nos debates do seu tempo.

\section{Referências}

MARICATO, E. O impasse da política urbana no Brasil. Petrópolis, RJ: Vozes, 2011 $-219 p$.

PÉCAUT, D. Os intelectuais e a política no Brasil - Entre o povo e a nação. São Paulo: Ática, 1990. 